\title{
Research on Online and Offline Blended Teaching Mode of Operations Research
}

\author{
Haiyan $\mathrm{Tu}^{1, *}$ \\ ${ }^{1}$ Department of Defense Economics, Army Logistics Academy, Chong Qing, China \\ *125647396@qq.com
}

\begin{abstract}
Online and offline blended teaching is a kind of teaching method under the condition of information support, which has attracted much attention. It is a new mode of curriculum quality reform in higher education. "Operations research" course design with online self-study activities as the leading, offline case discussion as the main body, build a knowledge system architecture as the core of the "Trinity" blended teaching mode, applied to the procurement logistics professional practical teaching, promoting students' learning investment, quantitative analysis in training students' thinking ability has achieved good results in cultivating, as well as operations research curriculum teaching reform provides a practical and feasible reference model.
\end{abstract}

Keywords: Operations Research, Teaching Reform, online and offline, Blended Teaching

\section{PREFACE}

Operations research is an important professional background course in the teaching system of College purchasing logistics, which is difficult in content, large in calculation, and closely combined with theory and practical application. Because of the complexity of teaching content, the traditional classroom teaching mode cannot meet the teaching needs of operations research courses. Students are afraid of difficulties and difficult to improve teaching efficiency. The blended teaching mode which combines the advantages of independent online Learning and offline research and communication has been gradually favoured [1]. Combining with the teaching reform of operations research course, it is an inevitable trend to improve the efficiency of classroom teaching by using the online and offline blended teaching mode.

\section{THE NECESSITY OF TEACHING REFORM OF OPERATIONS RESEARCH}

Operations research is a new interdisciplinary subject with strong practicality. It mainly studies how to use quantitative methods to make overall planning for the utilization of various resources, so as to maximize the benefits of limited resources and achieve the optimal overall goal. The purpose of this course is to cultivate students' ability to comprehensively use the theory and knowledge of operations research, solve practical problems through mathematical modeling and application of related software. The development of computer technology has brought the rapid growth of computing speed, just to meet the needs of complex precision computing in the process of the integration of operations research and a variety of cross disciplines.

\subsection{Adapt to the trend of scientific and technological development}

At present, the scientific and technological revolution is accelerating, with the rapid development and wide application of the new generation of information technologies, such as artificial intelligence, big data and block chain, have brought profound changes to the way of impart and acquire knowledge. The traditional education concept and teaching mode have been difficult to meet the learning needs of students. Taking advantage of the opportunity of information technology and current curriculum teaching reform, we should change the form of one-way transmission, shallow interaction and lowlevel training in operations research teaching. Through the curriculum teaching mode reform, we should apply advanced education theories, update education ideas, optimize teaching strategies, and innovate independent, intelligent and diversified teaching mode. 


\subsection{Effective measures to improve the ability of talent team}

At present, there is a shortage of famous teachers and top-notch talents. Some teachers cannot grasp the characteristics and rules of modern education and teaching, especially the teaching ability of young teachers needs to be enhanced. There is a certain gap between the overall ability and quality of the team and the requirements of talent training. Change the traditional phenomenon of teachers fighting alone, with the domain experts lapping teaching materials contents, teaching methods and learning methods, intelligence building an online courses, connect all teaching elements with information technology, implement Omni-directional and whole process of teaching innovation, sharing of information resources, speed up the wide spread of knowledge, which is also advantageous to the rapid growth of the young teachers.

\subsection{Important links to improve the quality and efficiency of teaching management}

Scientific and effective curriculum management is a powerful guarantee of teaching quality. Teaching mode is a key link between top-level design of talent cultivation and curriculum teaching implementation. Online and offline blended teaching mode can establish a closedloop management of the whole process from the top to the end. According to the teaching objectives of the course, the main teaching contents and methods, teaching schedule and teaching environment are designed. Online teaching follows the concept of open learning, and uses the functions of communication and discussion, online evaluation and online performance feedback to dynamically record the students' detailed learning process. Offline classroom teaching determines the classroom content according to the students' online learning situation, and adopts classroom question and answering, group interactive discussion and other teaching forms to deepen the content, so that students can internalize and deeply absorb these contents.

\section{EXPLORATION PATH OF OPERATIONS RESEARCH TEACHING MODE}

According to the characteristics of operations research curriculum, the curriculum system is reconstructed, which focuses on model and principle, theory and technology, skills and application. According to the idea of ability orientation, learning as the main body and wisdom integration, the exploration path of online and offline blended teaching mode is established.

\subsection{Highlight the characteristics of application ability and design clear and measurable teaching objectives}

To achieve the accurate docking with the ability needs, we must take the practical application of ability as the foothold and focus of the design of curriculum teaching objectives. The first is to establish systematic teaching objectives. Docking purchase logistics professional positions competency standards, according to the specific requirements of knowledge, ability and quality, the four levels of "general goal, sub goal, unit goal and classroom goal" are distinguished. The teaching goal of operations research course is deduced step by step, and the teaching goal system is constructed to adapt to the future quality, meet the demands of post and focus on core competence. The second is the realization of quantified teaching objectives. In view of the fact that the traditional description of ability is relatively general and difficult to measure, according to the requirements of reachable and measurable practical quantified curriculum teaching objectives. On the one hand, the goal of "know, understand and master" and other descriptive level is given the process conditions to achieve the goal. On the other hand, the degree of behavior is specified to the time, quantity, level and precision involved in the action verbs are quantified. Third, enrich the ideological and political teaching objectives of the course. According to the general vocational ability standard, It makes a comprehensive and systematic analysis of the ideological and political elements of the course, classifies and standardizes the direction of the ideological and political objectives of the course, and enriches the connotation of the objectives at all levels in accordance with the idea of "highlighting scientific literacy in structure and principle, dialectical thinking in theory and technology, and innovative thinking in skill and application".

\subsection{Grasp the knowledge and design ingenious and practical teaching content}

The teaching of operations research course has both theoretical knowledge and practical professional training. It has the distinct characteristics of integration of theory and practice. It must focus on the main line and integrate through. One is the integrated design of teaching content. According to the idea of "structure and principle highlight scientific literacy, theory and technology highlight dialectical thinking, skill and application highlight innovative thinking", optimize and integrate the teaching content, break the limitations of textbook chapters, link up the characteristics of various mathematical models, and create a variety of model comparison solutions with practical problem solving as the main line [2]. The second is to extend the teaching content of theory. Graduates need to have a strong ability of knowledge transfer. Based on the principle of typical problems, teaching needs to promote the transformation of theory and technology into 
general theory and generic technology, and extend the application of general problems to complex problems. The third is the teaching content of high-level design practice. Focusing on cultivating students' ability to solve practical and complex problems, it can improve the practical difficulty of skills and application by optimizing practical links, so that students can imperceptibly generate high-level abilities such as problem solving, analysis and decision-making in coping with challenges.

\subsection{Design teaching strategies supported by information to adapt to the characteristics of resource conditions}

Operations research has high requirements for practical operation and difficulty, so it is necessary to innovate the teaching organization mode, use diversified technical means and improve teaching efficiency. The first is to customize and optimize teaching methods according to needs. There is no fixed way to teach, and there is also a way to teach. To cultivate students' innovative thinking, it should base on the carrier of teaching content, follow the law of ability generation, and select teaching methods scientifically. The process of teaching implementation is designed as interest stimulation, thinking inspiration, knowledge internalization, ability shaping, transfer and application. It is closely related to the target requirements and content characteristics of each stage. It is targeted to choose such teaching methods as question type, discussion type, exploratory type, project type and task type, so as to effectively promote students' active participation, inspire students' deep thinking and comprehensively improve the ability of problem-solving. The second is to expand the boundary and optimize the teaching process. The classroom is tangible and shapeless. Focusing on students' full participation and deep participation in teaching, the teaching process is designed in accordance with three stages: pre-class, in-class and after-class [3]. Before class, it is important to guide students to inspire thinking, stimulate learning desire and inspire wisdom in advance through basic knowledge. In class, it is important to guide students to carry out discussion, deepen learning and solve problems in combination with the teaching content. After class, through the arrangement of case analysis, plan making and other expansion tasks, guide students to sublimate the teaching effect, realize the ability generation and consolidate the development wisdom. The third is to construct information enabling environment. Relying on the teaching system combining online courses and classroom teaching, software demonstration and practical training, the intelligent teaching solution with the characteristics of operations research is customized to realize the visualization of operation, scientific analysis, intelligent evaluation, diversified communication and resource sharing.

\subsection{Highlight the multi-dimensional characteristics of evaluation and design the assessment method combining explicit and implicit}

Curriculum assessment should not only pay attention to the students' learning effect of basic knowledge and theory, as well as the explicit assessment of ability generation, but also pay attention to the assessment of implicit ability such as thinking innovation, communication and expression. In the past, it is difficult to test the whole teaching effect by a single evaluation method, so it is necessary to carry out the evaluation in the whole process and multi-dimensional with both explicit and implicit ability. First, comprehensive assessment of dominant ability. In the traditional written examination and practical examination in the whole process of course teaching, it introduce many kinds of examination forms, such as problem traction and case discussion, which not only test the mastery of knowledge, but also the ability to use knowledge to solve practical problems, so as to enhance the comprehensiveness and systematicness of course examination. The second is to evaluate the recessive ability in the whole process. In view of the lack of attention and necessary means in the evaluation of students' recessive ability, the training requirements of curriculum recessive ability are subdivided into four categories of 24 evaluation indexes, including home country feelings, professionalism, cooperation and language expression, and the evaluation scale is used to quantitatively assess the realization degree of students' quality training objectives, so as to ensure the comprehensive and objective evaluation.

\section{TEACHING PRACTICE OF OPERATIONS RESEARCH COURSE}

The ultimate goal of curriculum teaching implementation is to improve teaching quality, the core is to establish the construction process, and the key is to connect the whole teaching implementation link by using the online and offline blended teaching mode. As a key link of curriculum reform, teaching mode should be closely linked to the quality of scientific design, innovative mode and fine implementation.

\subsection{Teaching process design}

Based on the practical analysis of operations research course characteristics and blended teaching characteristics, it reorganizes and designs the blended teaching mode process, teaching precursor, integrates traditional teaching resources, summarizes the basic knowledge points of self-learning precursor and mathematical model principle of online teaching, and points out the theoretical learning entrance. On the basis of students' classroom reports, classic case studies such as tourism backpack, logistics transportation, purchasing 
and storage are introduced to organize classroom group discussions, guide students to self-improve the knowledge system framework of operations research, and to supplement the knowledge integration of mathematical model building and problem solving [4]. Then, through the theoretical summary, the evaluation scale is used to evaluate the students' mastery of knowledge, and the design of teaching implementation scheme is revised retrospectively to form a closed-loop structure. The whole teaching process can be gradually improved to form a virtuous circle.

\subsection{Online activity design}

With the help of online courses, micro courses, case base, question bank and other ways, online activities of operations research enable students to learn independently individually, master the basic theories, methods and principles of operations research, and apply them to solve practical problems in professional fields, so as to achieve organic combination of interest and learning, and improve students' self-learning ability and ability to solve practical problems.

Online self-learning in order to increase the effect, group students to 3-5 people, a group discussion to submit learning outcomes such as online test or study report, the report should reflect the problems described, the actual problem of resource constraints, the problem model and resolving the problems, solve the same problems can use different models, the comparative analysis the advantages and disadvantages of various methods and make summary [5]. Finally, according to the students' discussion and practical demonstration, the students' self-learning situation is comprehensively evaluated, and the learning difficulties are grasped in the performance evaluation to adjust the classroom implementation content.

\subsection{Teaching implementation practice}

Classroom teaching lacks rich and vivid teaching resources, and online self-study can be organized to mobilize students' initiative. Online teaching lacks supervision of learning process and extensive interaction between teachers and students. The space-time consistency of curriculum implementation creates a bridge for emotional communication between teachers and students. Studying the online and offline blended teaching mode, adopting the combination of complementary advantages, constructing the teaching ideas of "structure and principle highlight scientific literacy, theory and technology highlight dialectical thinking, skill and application highlight innovative thinking" [6]. First, the teaching content should be matched with the actual business problems, and the curriculum should be guided to cover all the curriculum standards. The openness of case setting requires students to have a deep understanding of the basic concepts and principles of operations research related modules. The advanced deepening part is supplemented by case study, practical training and course summary. The second is to integrate the precursor network teaching into the course teaching, redesign the teaching process and organization mode, to follow a teaching philosophy as "problem for traction, case as the foundation, student as the main body, teacher as the guidance, aiming at ability", fully considering the characteristics of operations research and teaching features, implementing of "teaching resource distribution, student self-study, core knowledge lecture, group discussion, summarizes the evaluation" teaching steps, operations research has become an intelligent tool for quantitative analysis and scientific decision-making.

\section{CONCLUSION}

Operations research teaching pays attention to the integration of various elements in university, and pays attention to the interaction between teachers and students with materials in the form of communication. According to the characteristics of the course itself and the teaching characteristics, a blended online and offline teaching mode is designed to serve the operational research teaching with information elements. Blended teaching mode meets students' psychological demands for personalized learning, realizes timely and appropriate access to learning resources with the advantages of open and mobile learning, and enhances the mobile learning experience. The online and offline blended teaching mode can effectively solve the problems existing in the traditional teaching mode and is a new opportunity to improve the teaching effect.

\section{REFERENCES}

[1] C Yang,S Huan,Y Yang, A Practical Teaching Mode for Colleges Supported by Artificial Intelligence,International Journal of Emerging Technologies in Learning, pp. 152-158.

[2] J. Shi, Z. Chen, Research on Online and Offline Blended Teaching Mode and Multiple Assessment System Based on MOOC+SPOC, International Conference on Education Science \& Economic Management, XiaMen,China,2018,pp.321-326.

[3] F.L. Liang, W.H. Xia, Research and application of SPOC teaching mode based on MOOC resource, Computer Generation, 2017, pp. 220-228.

[4] J. Xin, A Research on the Construction of Online and Offline Mixed "Golden Class" Based on MOOC+SPOC Mode: A Case Study in Business English Reading and Writing(BERW), International Conference on Artificial Intelligence and Education (ICAIE), TianJin, China,2020, pp. 163-169. 
[5] Z. Zhang, Existentialist Philosophical Reflection and Correction of College Online Teaching -- Based on the Application of Blended Teaching Model, Jiangsu higher education, JiangSu, China, 2020,pp.136-138. DOI: CNKI:SUN:JSGJ.0.202009-012

[6] K. Qu, Numerical Analysis Teaching Method and Research Based on Online and Offline Blended Teaching Mode, Educational Research,2020, pp.118-120.DOI:10.32629/er.v3i3.2525 